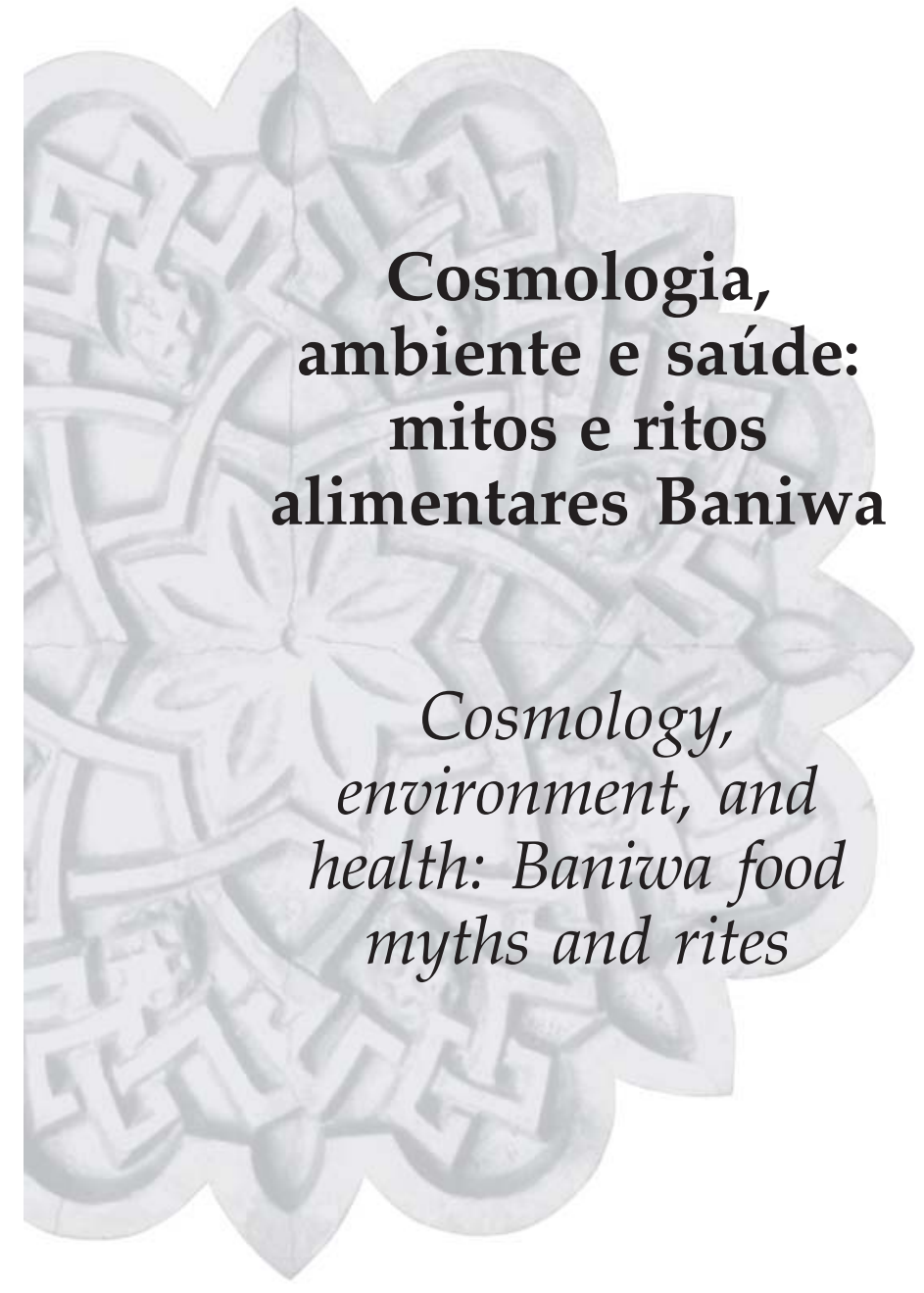

GARNELO, Luiza. Cosmologia, ambiente e saúde: mitos e ritos alimentares Baniwa. História, Ciências, Saúde-Manguinhos, Rio de Janeiro, v.14, suplemento, p.191-212, dez. 2007.

O povo Baniwa, grupo Aruak que vive no Noroeste amazônico, possui rica tradição mítica que influencia a expressão das dimensões políticas, éticas e práticas da vida social e orienta conhecimentos ancestrais que garantem a sobrevivência do grupo em condições ambientais adversas. $\mathrm{O}$ artigo analisa mitos e ritos estruturados em torno das fontes alimentares pesqueiras, em íntima interação com as explicações cosmológicas sobre a origem dos deuses, dos cursos d'água e dos micro-ecossistemas que favorecem a reprodução da fauna aquática. A mitologia Baniwa remete os processos reprodutivos dos peixes a um conjunto de relações sociais travadas entre sociedades humanas e não-humanas. Predação e comensalidade, noções subjacentes aos ritos alimentares, são concebidas como parte de um conjunto de práticas que visam à produção e manutenção das alianças de parentesco, à redução da periculosidade do alimento/presa e à manutenção do equilíbrio no balanço cósmico que garante a vida.

PALAVRAS-CHAVE: etnologia; índios sulamericanos; cosmologia; ambiente; saúde indígena.

GARNELO, Luiza. Cosmology, environment, and health: Baniwa food myths and rites. História, Ciências, Saúde Manguinhos, Rio de Janeiro, v.14, supplement, p.191-212, Dec. 2007.

The Baniwa people, a member of the Aruak group which lives in the northwestern Amazon, has a rich mythic tradition that influences how the political, ethical, and practical dimensions of their social life are expressed and that guides the ancestral knowledge that guarantees the group's survival under adverse environmental conditions. The article analyzes myths and rites built around fish as a food source; these have an intimate relationship with cosmological explanations of the origin of the gods, water bodies, and the microecosystems that foster the reproduction of aquatic fauna. Baniwa mythology draws an association between the reproductive processes of fish and a set of social relations involving human and nonhuman societies. Predation and edibility - notions underlying food rites - are viewed as part of a set of practices meant to produce and maintain kinship alliances, ease the food/prey peril, and maintain the cosmic balance that sustains life.

KEYWORDS: ethnology; South American Indians; cosmology; environment; indigenous health. 
E ste texto é produto de pesquisa mais ampla ${ }^{1}$ que vem sendo realizada desde 2004 na área indígena Baniwa, região do médio rio Içana, município de São Gabriel da Cachoeira, estado do Amazonas. Na etapa aqui abordada, priorizou-se o simbolismo da alimentação - mais especificamente as fontes alimentares pesqueiras - $\mathrm{e}$ suas inter-relações com a saúde, o ambiente, a cosmologia e as condições de vida do grupo.

O povo Baniwa ${ }^{2}$ é um grupo Aruak cujos assentamentos distribuem-se ao longo dos rios Içana e Aiari, afluentes do rio Negro. O parentesco está estruturado por meio da reunião de consangüíneos em três fratrias nomeadas (Walipere, Hohodene e Dzawenai), ${ }^{3}$ falantes da mesma língua, que mantêm entre si relações cerimoniais e de afinidade. De forma ligeiramente distinta de outros povos indígenas rionegrinos, os Baniwa não praticam a exogamia lingüística e sim a exogamia frátrica, ainda que seja possível encontrar consortes falantes de outras línguas indígenas rionegrinas habitando em suas aldeias. Patrilinearidade e patrilocalidade são práticas sociais correntes.

O padrão de assentamento é fundado em uma divisão políticoterritorial dos grupos de consangüíneos, redundando na apropriação de micro-ecossistemas distintos, o que implica formas também variadas de acesso aos recursos alimentares. Assim, os membros de certas fratrias têm maior disponibilidade de terras agriculturáveis, ao passo que outros controlam lagos e igapós, fontes principais de pescado. A desigualdade da oferta de recursos necessários à reprodução material e simbólica da sociedade instituiu uma complexa rede de trocas entre as aldeias, mediadas por obrigações de reciprocidade entre consangüíneos e trocas matrimoniais entre afins (cunhados potenciais ou reais), gerando uma milenar relação de interdependência entre os assentamentos e garantindo a circulação de meios de subsistência.

Da complexa cosmologia Baniwa nos restringiremos, neste artigo, à referência de um conjunto de relações hostis travadas pela família ancestral - formada por Niãpirikoli, o deus criador, e seus irmãos Dzooli e Eeri - contra animais-espírito predadores como os macacos-trovões (Eenonai) e as grandes serpentes (Omawali), cujo controle do cosmos impedia que a humanidade pudesse prosperar. No tempo primordial Niãpirikoli tanto guerreia quanto busca esposas entre afins hostis como os peixes-piranha e as serpentes. São tentativas, freqüentemente mal-sucedidas de domesticação da alteridade agressiva, mas necessárias à constituição da vida em sociedade, instituída por Niãpirikoli e outros membros de sua família. Essa relação ambivalente com a alteridade - perigosa, mas imprescindível à reprodução da vida - é uma característica essencial ao modo de vida dos Baniwa, que buscam, e encontram, nos limites exteriores à sua sociedade, elementos essenciais à produção e transformação de sua própria existência. 
A cosmologia Baniwa coexiste com as transformações históricas enfrentadas no contato com o mundo não-indígena, o que tem acarretado diversas ameaças à sua subsistência. Entre elas destacam-se a sedentarização da população e a escassez lenta, mas progressiva, do pescado, cuja origem é atribuída por eles ao aumento da população e ao abandono de determinadas facetas de seu conhecimento ancestral. Esse abandono abala as crenças dos mais jovens nas características de uma natureza humanizada, prejudica a preservação de um comportamento adequado às relações interespécies e reduz o acervo de conhecimentos operativos sobre o entorno do qual retiram sua sobrevivência.

Porém o mesmo processo histórico vem engendrando um incremento de sua capacidade de negociação com o mundo globalizado, feita através das associações indígenas que os representam junto às instituições do mundo não-indígena. A atuação no movimento etnopolítico tem levado diversas lideranças a reconhecer que seus saberes sobre a natureza podem operar como moeda de negociação com entidades ambientalistas, favorecer o acesso a mercadorias e a políticas de desenvolvimento sustentável que consideram essenciais ao modo de vida que adotaram. Nesse contexto, observa-se nas aldeias Baniwa uma retomada organizada do ensino-aprendizado dos antigos conhecimentos sobre a natureza, uma busca por motivar os mais jovens a aprofundar seu conhecimento sobre o tema e a desenvolver meios de preservação das fontes pesqueiras ameaçadas e um renovado interesse pelas relações cosmológicas que regem sua existência.

\section{Aporte teórico-metodológico}

No âmbito etnográfico a pesquisa é tributária de Robin Wright (1993, 1993-1994, 1998) e de Jonathan D. Hill (1993, 1984, 1987; Hill, Morán, 1983), cujos estudos sobre a cultura Baniwa como um todo e, em particular, sobre os ritos que os Baniwa denominam Pudali e Kalidzamai demonstram a íntima relação entre a cosmologia do grupo, as trocas matrimoniais, mediadas pela oferta recíproca de alimentos entre afins, e os ritos de pós-nascimento, caracterizados pela ação xamânica sobre os alimentos acessíveis ou interditados à família pós-natal. São elementos essenciais para o entendimento da relação entre cultura e natureza nessa sociedade.

Entre os estudos na etnologia do Noroeste amazônico, são relevantes para nossa abordagem os trabalhos de Christine Hugh-Jones (1979), que analisou as correlações entre cosmologia e produção e consumo de alimentos no Noroeste da Amazônia indígena; Kaj Arhem (2001), que estudou os circuitos alimentares Makuna, situando-os como parte de uma rede de relações sociocósmicas; Aloisio Cabalzar (2005), que efetuou um 
levantamento do conhecimento dos grupos Tukano e Tuyuka sobre os peixes; e Dominique Buchillet (1988), que analisou correlações entre a produção de doença e a simbolização da natureza pelos Desana.

Em um plano mais geral, Eduardo Viveiros de Castro (1996, 2002) traz categorias analíticas relevantes no modo como trataremos os dados colhidos entre os Baniwa. Uma contribuição importante desse autor é o conceito de perspectivismo, caracterizado por ele como uma ontologia nativa em que tanto humanos quanto animais são vistos como pessoas dotadas de intencionalidade e volição. De acordo com Viveiros de Castro (1996), para as sociedades indígenas amazônicas haveria uma unidade de espírito entre humanos e animais, ao lado de uma distinção de corporalidades zoomórficas e antropomórficas em coexistência. Tal proposição tem importante implicação teórica no entendimento das relações travadas pelas sociedades indígenas amazônicas com a natureza.

Em que pesem algumas divergências acerca de particularidades analíticas que envolvem a idéia do perspectivismo, vemo-la partilhada por autores como Philippe Descola $(1999,2001)$ e Carlos Fausto (2002). Ambos concordam que em grande parte das culturas indígenas sul-americanas vige a idéia de que os seres da natureza são dotados de 'agência' e partilhariam com a humanidade uma unidade de espírito, ao lado de uma diversidade de manifestações corporais. De acordo com essa cosmologia, humanos e animais gozariam da capacidade auto-reflexiva, atribuindo a si próprios a condição de sujeitos. Entretanto para os humanos os animais seriam vistos tanto como sujeitos quanto como presas. Os animais, por sua vez, veriam os humanos como predadores e, em algumas circunstâncias, também como presas. Em seus próprios domínios os animais teriam capacidade antropomórfica, desenvolvendo, tal como nós, intensa vida social em seus locais de moradia. Em suma, em uma rede de interações sociocósmicas desse tipo, a posição de cada sujeito é relativa ao ponto de vista que ele assume, gerando-se uma perspectiva dinâmica na qual a definição da posição 'outro' é sempre inversa daquela reconhecida pelo sujeito para si mesmo.

Esse modo de apreender as relações entre os seres não comporta uma oposição entre cultura/sujeito e natureza/objeto; pelo contrário, trata-se de um campo intersubjetivo que congrega humanos e animais, ainda que cada um dos termos dessa relação assuma uma perspectiva simétrica, mas invertida, na apreensão que faz do outro. Na concepção nativa os cosmos é ordenado em um modelo sociocêntrico, usado para atribuir sentido a um conjunto de relações sociais e contratuais que ultrapassam as fronteiras da sociedade humana e a entrelaça com outros modos de vida, não-humanos mas organizados de modo semelhante à nossa própria existência (Descola, 1998; 
Viveiros de Castro, 1996). Ressalvam os autores que a condição de sujeito não é indiscriminadamente aplicada a qualquer animal, sendo mais especificamente atribuída aos grandes predadores que podem estabelecer relações diretas de competição com os parceiros/ rivais humanos.

Para Descola (1998), segundo o ponto de vista das sociedades ameríndias há uma "diferença de grau, e não de natureza, entre os homens, as plantas e os animais" (p.25). Ele remete o entendimento da lógica que rege as relações com a natureza aos sistemas cosmológicos e sociológicos produzidos por cada sociedade indígena imersa nessa teia de relações sociais. Também informa que, com freqüência, a interação dos humanos com os animais é vista como “... uma relação entre afins e marcada pela mesma rede de obrigações que é característica das relações entre parentes por aliança" (p.36).

Fausto (2002) empreendeu uma releitura dos trabalhos supracitados, partilhando com eles as premissas gerais do perspectivismo mas interpretando as relações entre cultura e natureza como um "sistema sociocósmico no qual o objeto em disputa é a direção da predação e a produção de parentesco" (p.11). Para tal fim, prioriza a análise da comensalidade e da predação, vistas como modos de produção da dinâmica interior da vida social. Enfoca a alimentação como um dispositivo de produção de corpos aparentados (p.8). Para o autor, o ponto essencial da discussão é o exercício da capacidade reprodutiva exercida por uns (os predadores) sobre outros (os caçados), em situações em que as presas, transformadas em alimento, reforçam os vínculos entre comensais, promovem obrigações recíprocas e solidárias e contribuem para a redução das diferenças entre os membros do grupo.

No noroeste amazônico, Arhem (2001) descreveu a interconexão entre os humanos e a natureza em uma etnografia sobre os Makuna. A cosmologia do grupo é descrita pelo autor nos mesmos termos totalizantes usados para caracterizar as interações travadas entre sociedades humanas e não-humanas, expressando-se como um sistema de relações que o autor denomina 'ecocosmológico'. Nele, os seres humanos estariam em uma posição central, sendo representados simultaneamente como predadores e presas. Em um dos pólos da relação, situar-se-iam os espíritos comedores de homens, representados por grandes predadores como o jaguar, as anacondas e outros entes ameaçadores; no outro extremo do gradiente estariam os seres que são apenas comida, ou seja, que não ameaçam os humanos de predação. Ali a morte de uma presa representa ao mesmo tempo subtração (tira-se a vida, consome-se um elemento constitutivo do sistema de relações) e adição (a morte da presa provoca a reintrodução de sua alma nas casas de origem de humanos e animais, propiciando seu renascimento e repovoamento do mundo dos vivos). A caçada contribui para a restauração de um balanço 
adequado do equilíbrio do cosmos. O mesmo raciocínio é usado pelos Makuna para a morte de qualquer presa, seja animal ou humana; neste último caso, os predadores costumam ser os espíritos comedores de gente.

O enfoque do Arhem (2001), tal como a maior parte da literatura disponível sobre o tema, é dirigido aos animais de caça. Ele refere, de forma breve, em um único parágrafo, que as formas de intercâmbio entre humanos e peixes é diferente, já que entre os Makuna os peixes "são o protótipo do alimento animal para os seres humanos" (p.228), ou seja, a interação entre peixes e pessoas humanas estaria amparada pelo princípio da reciprocidade generalizada e não-equilibrada, remetendo os peixes para o pólo da comida, sem capacidade de retaliação à sua pesca pelos seres humanos.

Como veremos adiante, boa parte dos achados de Arhem (2001) entre os Makuna também pode ser vista entre os Baniwa. Há porém uma diferença essencial, no que se refere à interação entre humanos e peixes. Ao longo texto tentaremos demonstrar que, na cultura Baniwa, os peixes são detentores de 'agência', mostrandose capazes de causar danos através de diversos meios, particularmente a doença. Entre os Baniwa os peixes não são designados através de uma classificação genérica, como ocorre entre os Makuna, mas sim alvo de conhecimento detalhado, com identificação precisa de espécies. As narrativas míticas e os benzimentos de comida trazem informações minuciosas sobre as diversas serpentes que seriam 'pais' e 'mães' de famílias específicas de peixes, evidenciando uma ligação direta entre os peixes e os espíritos-serpentes, os quais, para Arhem, ocupam a posição exclusiva de comedor de homens. Situação semelhante aos nossos achados foi evidenciada por Cabalzar (2005), em seu estudo sobre os Tuyuca, outro grupo indígena que vive no noroeste amazônico, no lado brasileiro.

A literatura supracitada tem trabalhado os dados relativos à caça como eixo de análise da relação dos humanos com a natureza. Parte de nossa pesquisa de campo é direcionada para o entendimento da interação com os animais terrestres, porém consideramos que as características da informação obtida entre os Baniwa nos autorizam a utilizar, para a análise da interação com os animais aquáticos e da pesca, o mesmo marco teórico já desenvolvido para caça, em estudos junto a outros grupos ameríndios sul-americanos.

\section{Apresentação e discussão dos dados}

Na cosmologia Baniwa, a família ancestral, formada por Niãpirikoli, seus dois irmãos e seu filho Kowai, é responsável pela criação do mundo, pelo estabelecimento dos ritos de passagem, regras matrimoniais e relação de parentesco, bem como pelo surgimento das plantas cultivadas (alimentares e medicinais), técnicas 
de manufatura das habitações, artes de pesca e outras. A epopéia de criação e organização da vida social é preservada pelos Baniwa em um conjunto de narrativas míticas coerentes e articuladas entre si, formando um longo e interconectado relato que, no conjunto, nos auxilia no entendimento das conexões entre a origem e organização primordial do mundo e as ações ordinárias da vida cotidiana, para as quais oferecem parâmetros gerais de orientação, ainda que possam ser reinterpretadas segundo o contexto em que se apresentem (Lévi-Strauss, 1993). No caso das relações com a natureza, elas se caracterizam, com no dizer de Arhem (2001) para os Makuna, em "cosmologia convertida em ecologia" (p.232).

Um grande conjunto de narrativas que trata da origem dos rios, dos lagos, igapós e outros locais de pesca, bem como do surgimento das diversas espécies de animais aquáticos, com suas formas específicas de vida social - vistas como análogas à forma humana de viver - pode ilustrar as discussões aqui travadas. Segundo os mitos, a criação do rio Içana foi conseqüência de um conflito de Niãpirikoli com o pássaro Keerao, que embora fosse amigo do herói havia mantido relações sexuais com a esposa dele enquanto este buscava a noite, até então inexistente no mundo. Aborrecido com o incidente, o criador tentou matar Keerao por meio de feitiçaria xamânica, mas foi mal sucedido. Em revide a essa agressão, o pássaro criou uma grande enxurrada, com a qual pretendia matar o desafeto, mas embora a magia tenha inundado o mundo todo, o pássaro não conseguiu alcançar seu intento. Aos poucos a água foi 'criando caminho' para si e formou os cursos d'água - o trecho mais longo e volumoso formou o rio Içana -, e nos locais onde a água empoçou formaram-se os lagos.

O mundo primitivo de Niãpirikoli era pequeno; só depois, sob a ação das flautas mágicas de Kowai, ele expandiu-se e atingiu as dimensões atuais. O rio Içana seguia o mesmo padrão: era curto e estreito. Para ampliar os locais de pesca e de moradia dos futuros humanos, Dzooli, irmão de Niãpirikoli, mobilizou os poderes mágicos dos cânticos malikai (que os narradores traduzem para o português como 'benzimentos') e do tabaco. Soprou a fumaça de seu cigarro na direção do rio, ampliando dessa forma o seu curso. De acordo com os narradores, essa também é a origem das muitas curvas do rio, que surgiram da trajetória tortuosa da fumaça carregada pelo vento.

Quando a água baixou, Niãpirikoli resolveu criar vida para povoá-la. Criou os peixes a partir de pedaços de madeira e lhes deu vida com o sopro do tabaco e os cânticos malikai. Do sol o criador retirou as cores com que fez as pinturas corporais dos peixes, conferindo identidades distintivas para cada espécie. Porém os primeiros peixes eram moles, porque não tinham espinhas, e portanto também não tinham agilidade. Incapazes de nadar longas distâncias, 
não se afastavam do porto da aldeia ancestral, o que inviabilizava a colonização dos cursos d'água. Niãpirikoli mobilizou poderes mágicos das quatro direções do firmamento, canalizou-os para a fumaça de seu cigarro e soprou-a sobre os peixes, criando as espinhas que hoje os caracterizam. Os peixes que fazem piracema foram dotados de ossos mais robustos e se tornaram aptos a percorrer longas distâncias até os locais de desova. Em outro episódio, Dzooli benzeu-os, nomeou-os, ensinou-os a dançar, a construir malocas, determinou as regras de matrimônio e estabeleceu as formas de reprodução e os locais de desova de cada espécie.

As conseqüências desses eventos geram desdobramentos contraditórios. De acordo com algumas versões frátricas, os peixes criados por Niãpirikoli cresceram e multiplicaram. O crescimento (em tamanho e poder mágico) de alguns deles transformaram-nos em grandes serpentes (Omawali), dotadas do poder de criar novos peixes, e se tornaram então os 'pais' e 'mães' dos peixes. No modo Baniwa de classificar os animais, os peixes e as grandes sucuris pertencem a um mesmo nicho taxonômico, ou seja, são consangüíneos. Em outras variantes, os narradores afirmam que as grandes serpentes sempre existiram e que já eram pais e mães de alguns tipos de peixes, diferentes daqueles criados por Niãpirikoli.

Existem diversas versões míticas que tratam da origem dos peixes. O traço comum entre elas é atribuir às grandes serpentes - e à sua descendência, os peixes - a condição de inimigos perigosos da humanidade (walimanai), que deles depende para se alimentar. A ameaça representada pelos peixes não se distribui uniformemente: as espécies portadoras de dentes e ferrões, ou cuja morfologia se pareça com a das serpentes, são consideradas as com maior potencial de dano aos humanos.

Algumas narrativas sobre o povoamento dos lagos mostram com muita clareza a tensão entre Niãpirikoli (e seus aliados) e as sucuris, que dominavam os grandes lagos e, por serem predadoras dos humanos, inviabilizavam os assentamentos destes nas proximidades. Em uma dessas narrativas, Niãpirikoli e seus familiares guerreiam com as cobras, matando-as ou expulsando-as dos lagos a fim de proporcionar espaço a ser ocupado pelos futuros humanos. A derrota das serpentes era condição essencial para o acesso humano às fontes pesqueiras, importantes para a sobrevivência. Finda a luta, facilitou-se o caminho da humanidade à pesca abundante, mas como conseqüência a grande capacidade multiplicadora dos peixes também desapareceu junto com as serpentes hostis.

Depois Niãpirikoli mobilizou os poderosos pajés-onça, antepassados da atual fratria Dzawenai, ${ }^{4}$ que recriaram os 'pais' e as 'mães' dos peixes para repovoar os lagos onde os humanos pescariam. Essa narrativa, de notável precisão geográfica, descreve uma epopéia de descida do rio Içana, durante a qual os xamãs Wakaweni 
esculpem serpentes em toras de madeira, em cuja superfície desenham pinturas que conferem características distintivas a cada uma delas. Na seqüência, por meio de cânticos e fumaça do tabaco, conferem vida aos novos seres. O passo seguinte é encontrar locais de moradia adequados a cada 'mãe de peixe' criada. Para esse fim, os xamãs entram em transe e mergulham até o fundo de cada lago, buscando conhecer as características de cada um deles e avaliar compatibilidades entre a entidade e sua habitação.

$\mathrm{Na}$ linguagem corriqueira, os lagos podem ser designados genericamente por kophé kooyanali (casa de peixe), mas nos benzimentos recebem nomes específicos, conhecidos apenas pelos especialistas e que lhes foram conferidos pelos Wakaweni nos rituais de criação das mães de peixes. Os nomes dos lagos e das serpentes que neles passaram a habitar é recitada seqüencialmente nos rituais de pós-nascimento (kalidzamai), parte importante dos rituais de proteção do jovem humano contra o perigo dos alimentos que ingerirá ao longo da vida.

Através do canto, da dança e da fumaça do tabaco os aliados de Niãpirikoli repovoam os lagos com as serpentes criadas pelo poder da família ancestral. Ainda que permaneçam essencialmente como predadores perigosos, a (re)criação xamânica promove certo grau de 'familiarização' ${ }^{5}$ das grandes serpentes, capaz de possibilitar uma relativa convivência com os humanos. A nomeação e o repovoamento dos lagos cumprem também o papel de influenciar na delimitação dos territórios frátricos (ou seja, traça fronteiras internas dos grupamentos humanos), que se superpõem aos territórios ocupados pelas sociedades de peixes-serpente e outros animais-espírito, em uma coexistência que permanece conflituosa.

$\mathrm{Na}$ cosmologia Baniwa, os peixes e os ancestrais da humanidade mantêm relações de afinidade, ao passo que os pássaros costumam figurar nos relatos como aliados próximos ou consangüíneos. Niãpirikoli teve várias esposas, a maioria delas oriunda de famílias de peixes predadores. Em um mito que trata do surgimento da pimenta, por exemplo, o herói está casado com a filha do peixepiranha, em episódio que narra a visita que o herói faz à casa do sogro, acompanhado de diversos pássaros. A narrativa enfatiza a posição ambígua de Niãpirikoli, que se alimenta dos consangüíneos de sua mulher e de seu sogro. Ela explica não apenas o surgimento da pimenta (criada por Niãpirikoli para 'cozinhar' o peixe cru que é servido e neutralizar o veneno nele contido, com o qual o sogro pretendia matá-lo), mas também o de uma doença (whíokali) ligada à ingestão de peixe cru ou mal cozido, cujas secreções podem destruir as entranhas da vítima. O período de permanência na casa do sogro é palco de uma série de tentativas de assassinato, das quais o Niãpirikoli consegue escapar graças a sua engenhosidade e seu poder xamânico. Como saldo permanente do episódio, sobram a pimenta e da doença whíokali (Garnelo, Wright, 2001). 
Outras narrativas representam a pesca como produto de jogos eróticos travados entre mulheres-peixes e pescadores míticos ou humanos. Entre os Baniwa, a pesca, uma atividade essencialmente masculina, é revestida de forte conotação sexual e exige a realização de ritos propiciatórios que visam conferir eficiência às armadilhas de pesca e ampliar o sucesso do pescador. Os ritos demandam a execução de benzimentos, o uso de plantas de sedução (monotsi) e a abstinência sexual e alimentar. Em conjunto, tais procedimentos visam realçar o poder de atração do pescador e conferir eficácia às artes de pesca. Trata-se de um sistema de trocas em que a corte bem-sucedida às mulheres-peixes implica a renúncia aos prazeres, na vida ordinária do pescador. A análise das características da pesca permite apreendê-la como um amplo conjunto de práticas e concepções ordenadas em uma rede de interações que favorece o pescador.

$\mathrm{O}$ intercurso sexual entre membros de sociedades humanas e não-humanas é tratado em diversos relatos míticos. Em um deles, de particular importância na cosmologia do grupo, a grande serpente Oliámali manteve relações sexuais com uma das mulheres de Niãpirikoli e a engravidou. Trata-se de uma porfia pela produção de descendentes, humanos ou peixes, que herdarão o controle do mundo. No desfecho, a serpente adúltera e sua descendência são mortas, garantindo-se a ordem atual na qual os peixes tornaramse presas dos humanos. A pesca cotidiana é vista como uma atualização invertida desse evento mítico, uma vez que, aos perdedores do embate em que a descendência humana quase foi inviabilizada, atribui-se o papel de sustento da prole dos Baniwa.

Entre as diversas versões sobre a origem dos peixes, há um mito muito apreciado nas aldeias. Quase todos conhecem a história de Hiwidamitti ('cabeça de moqueado'), um jovem pescador que desobedece às orientações de seu irmão mais velho e, incapaz de resistir ao atraente cheiro do moqueado, come o peixe oferecido pelos Iñame, os espíritos de mortos. Algum tempo depois as partes do corpo de Hiwidamitti se autonomizam, ganham vida e se transformam em vários tipos de peixes, só lhe sobrando de humano a cabeça, que em um pulo se assenta no ombro de seu irmão. Ali se comporta de modo indevidamente voraz, apropriando-se de qualquer comida ofertada ao mais velho, que começa a morrer de fome.

A história de Hiwidamitti trata de um tema recorrente nas sociedades ameríndias, a questão da comensalidade com os mortos, já analisada por diversos autores, entre eles Fausto (2002). Ao ingerir o alimento dos mortos, Hiwidamitti ultrapassa uma fronteira que o afasta definitivamente da sociedade humana, tornando-se um transitante entre duas realidades inconciliáveis. Reduzido a uma cabeça e incapaz de conter seus impulsos, resta-lhe a condição de parasita até que seja morto por seus consangüíneos, que assim fecham uma perigosa porta de comunicação com a alteridade irre- 
dutível e ameaçadora. É uma trajetória que se repete em outras narrativas e demonstra, simultaneamente, o perigo e a renovação representados por planos de existência exteriores à sociedade Baniwa.

Outro episódio mítico retoma o tema do cruzamento da fronteira entre a sociedade humana e o domínio das serpentes primordiais. Poperiana, um dos lagos mais piscosos do médio Içana, era o local de moradia de uma grande sucuriju (Omawali), que ali criava diversos tipos de peixes, esculpindo-os em madeira e dando-lhes vida ao lançá-los nas águas. Embora fosse um rico manancial de pesca, o lago Poperiana era um lugar tão perigoso que os humanos não conseguiam passar por ali. Os viajantes eram obrigados a saltar das canoas e seguir a pé por caminhos abertos na mata, e somente retornavam ao rio após ultrapassarem os limites do lago.

Em certa ocasião, um passante que cruzava o lago em uma canoa com seu filho foi agredido pela serpente que ali habitava. $\mathrm{O}$ homem salvou-se, mas a criança desapareceu. Inicialmente o pai pensou que o filho havia morrido, mas foi informado por um boto que o jovem estava vivo e morava na maloca dos sucurijus, no fundo do lago. Na seqüência da trama, o pai empreende uma viagem à maloca subaquática, mata o sucuriju macho e resgata o filho. Tal desfecho reafirma o tema da disputa persistente entre humanos e serpentes pelo domínio das águas.

Em algumas versões a narrativa prossegue relatando as vicissitudes do pai com a mudança de comportamento do filho resgatado, que não consegue retomar a vida ordinária na casa paterna e perde-se em prolongados banhos, mostrando-se sempre relutante em sair da água. Incapaz de contê-lo e testemunhando sua progressiva transformação em animal, o pai finalmente concorda que ele parta para viver no ambiente aquático. Concluída a metamorfose a criança torna-se ela própria um quelônio, virando 'pai' dos bichos-de-casco, híbridos de animais aquáticos e terrestres. Essa transformação confere à serpente a vitória final sobre o humano que a assassinara, já que a criança resgatada, incapaz de superar o aparentamento com os animais aquáticos (causado por sua permanência na maloca das cobras), afasta-se definitivamente da humanidade. Entretanto a metamorfose também opera mudanças no mundo aquático, já que o garoto institui regras de casamento e ensina habilidades específicas de cânticos e danças aos diversos tipos de quelônios.

As mortes de sucurijus, tratadas nos mitos, são eventos marcados pela ambigüidade, pois se por um lado elas viabilizam o acesso dos pescadores aos peixes, por outro representam a perda da potencialidade reprodutiva desses animais. Nesse contexto, os homens limitam-se ao papel de predadores/consumidores dos animais aquáticos, destituídos que são da capacidade de reposição dos pei- 
xes, monopolizada pelas serpentes. A vivência que os Baniwa hoje expressam sobre o mundo aquático que os cerca é a de empobrecimento progressivo da população de peixes e perda iminente de suas fontes alimentares. Tais mudanças são situações atribuídas à morte ou a outras formas de distanciamento das fontes de poder que garantiam a reposição do pescado: as grandes sucuris.

Os hábitos dos peixes também são objeto de elaboração simbólica. Mitos e ritos falam de vida em sociedade, regidas por obrigações matrimoniais e de consangüinidade, semelhantes às dos próprios Baniwa. A piracema é equiparada à festa humana pudali. Acredita-se que, nessas festas, os peixes sobem os cursos d'água em busca das casas das serpentes ancestrais. Lá chegando cantam, dançam, realizam festivais de troca de alimentos, bebem caxiri e em seguida procriam. A vida social dos peixes também comporta rapto de mulheres, adultério, inveja, avareza e, por vezes, sexo forçado ou consensual com mulheres humanas. Diversas passagens míticas têm implicações no surgimento de doenças, nas restrições dietéticas adotadas em ritos de passagem, nas estratégias de cura ou cuidados com os doentes e em treinamento e práticas xamânicas.

A produção simbólica que oferece parâmetros de interação dos Baniwa entre si e com a natureza também tem expressão ritual. Nesse âmbito, dois importantes ritos foram estudados por Wright (1993) e Hill (1987; 1993). Em pesquisa desenvolvida na década de 1980, entre membros da fratria Dzawenai, na Venezuela, Hill (1993) caracterizou os malikai como um conjunto de canções, cânticos e orações executados em rituais de pós-nascimento, iniciação pubertária masculina e feminina e cura. A execução dos malikai é considerada, pelo autor, um tipo de mediação poético-musical, capaz de conectar os relatos míticos que tratam da origem e ordem do mundo com a experiência partilhada pelos humanos no transcorrer da vida social e na interação com a natureza.

Wright (1993) estudou a linguagem ritual dos cânticos kalidzamai das fratrias Hohodene e Walipere, no Brasil, considerada por ele uma variante da tradição, em contraponto aos dados analisados por Hill, entre os Dzawenai. Wright situa os cânticos kalidzamai como parte de um conjunto mais amplo de atividades xamânicas denominadas iapakana no falar Hohodene, ou ñapakana entre os Walipere. Segundo o autor, os iapakana têm como traço comum a recitação de certas fórmulas rituais 'sopradas' com a fumaça do tabaco, cujo uso teria a finalidade de potencializar o poder contido nas palavras. Elas podem ser usadas para obter sucesso em atividades cotidianas ligadas ao cuidado com as roças, para a promoção da saúde e cura de doenças, para obter êxito em caçadas e pescarias etc.

Wright (1993) identifica gradientes de poder e complexidade entre as fórmulas recitadas e aponta o rito kalidzamai, que associa cânticos e recitações, como um dos mais complexos e importantes 
tipos de iapakana. Em sua pesquisa o autor estudou detalhadamente os kalidzamai executados em rituais de pós-nascimento, de especial interesse na análise de nossos próprios dados sobre alimentação, razão por que sintetizamos a seguir seus achados sobre esse ritual. Pelo mesmo motivo fazemos também uma breve referência à pesquisa de Hill (1993) com teor similar, realizada na Venezuela.

De acordo com Wright (1993), os kalidzamai de pós-nascimento tanto visam proteger a criança e sua família da ação agressiva dos espíritos da floresta, da água e do mundo subterrâneo, quanto tornar segura a comida a ser ingerida pela dupla parental ao término do período de restrição alimentar, pós-parto. Os atos ritualísticos que reinserem o alimento rotineiro na dieta dos pais e do recémnascido compreendem uma sessão de recitações protetoras do corpo e espírito paternos, que antecede a caçada a ser feita pelo pai, ainda sob restrição alimentar, em continuidade ao processo ritual. A transformação da presa em alimento seguro exige a manutenção das recitações sobre o animal caçado e sobre a pimenta usada para temperá-lo (Hill, 1993; Wright, 1993). Wright (1993) afirma que a nomeação sistemática dos seres-espíritos, feita nos benzimentos, busca prevenir potenciais agressões - sobretudo doenças - que esses seres podem perpetrar em situações cotidianas da família. A recitação sobre a comida tem objetivo similar; nesse procedimento, o oficiante nomeia todas as espécies comestíveis, que são cozidas com pimenta, protegendo os pais e a criança da periculosidade intrínseca ao ato alimentar.

Outro rito de grande importância para o entendimento das relações entre meio social e natural, travadas pelos Baniwa, é o pudali, estudado por Hill (1987) entre os Dzawenai. De acordo com o autor, esse rito, que se caracteriza pela troca de alimentos entre grupos de afins, tem como objetivo maior, além das finalidades mais evidentes de redistribuir excedentes e de estabelecer trocas matrimoniais, instituir meios cerimoniais de abolição de diferenças entre consangüíneos e afins, entre homens e mulheres e entre humanos e não-humanos. Em seu estudo, o autor efetua minuciosa etnografia do pudali, da qual extrairemos apenas alguns pontos relevantes aos propósitos de nossa pesquisa.

Segundo o relato de Hill (1987), a realização de um pudali demanda a produção de um excedente de pescado, a ser ofertado a afins residentes em outra povoação. Na chegada os visitantes depositam a comida ofertada no pátio externo da aldeia, mas não adentram (e nem são convidados) as moradias dos receptores do alimento. Inicia-se, na seqüência, o primeiro conjunto de músicas e danças, executadas apenas pelos visitantes.

De acordo com a descrição de Hill (1987), o ritual é dividido em três estágios. No primeiro os visitantes tocam diversos instrumentos de sopro e executam um conjunto elaborado de danças em que pares 
ordenados de homens e mulheres evoluem em círculos ao redor da comida. Nessa fase as performances seriam uma imitação estilizada do comportamento reprodutivo do peixe aracu (Leporinus sp). No segundo estágio, pautado pela imitação do comportamento alimentar e reprodutivo do besouro déetu, os anfitriões aceitam a comida e em seguida convidam os visitantes a entrar nas moradias. O momento marca o início de uma interação social de partilha de comida e bebida e de execução conjunta de performances no interior da casa. Simultaneamente alguns convidados postam-se do lado de fora da casa e tocam as longas flautas déetu, cujas extremidades, através de orifícios nas paredes da casa, penetram no interior dela. Tal performance simboliza a superação dos limites internos e externos da sociedade. Finalmente, no terceiro estágio, anfitriões e convidados já efetuaram trocas recíprocas de alimentos e bebidas e, em clima de familiaridade e informalidade, executam músicas e cânticos livremente improvisados - que também representam o comportamento dos peixes e outros animais -, em completa abolição da distinção entre convidados e anfitriões.

Para Hill (1987) as três fases descritas simbolizam um processo de desconstrução e transcendência das fronteiras reconhecidas pelas culturas humanas. A etapa inicial do rito, marcada pela expressão de estranheza e desconfiança devida a um afim, é seguida pelo momento de abolição dos estigmas que distinguem parentes e afins. A segunda fase propicia a chegada ao momento final do rito; é um patamar em que as próprias barreiras entre os dois sexos e as que separam humanos e não-humanos são temporariamente abolidas, instaurando-se um clima de aproximação e familiaridade entre os diversos espaços socializados que formam o cosmos Baniwa.

Entretanto não só os momentos extraordinários são passíveis de ritualização que expressa conexões entre a vida humana e a ordem cósmica. Tal como ocorre com as artes de pesca, o preparo e consumo cotidiano de alimentos guardam características rituais que também exemplificam os modos Baniwa de interagir com a natureza.

A manipulação do pescado exige cuidados especiais, por parte do pescador, de modo a evitar a ingestão acidental de peixe cru ou de suas secreções, sobretudo do chamado pitiú (heewe) do peixe, fonte de diversas doenças. A origem desse atributo animal é objeto de detalhado relato mítico, no qual os peixes, inicialmente sem pitiú, teriam incorporado às suas características físicas o sêmen transmutado da grande serpente Oliámali, a mesma que foi morta por Niãpirikoli. A potencialidade agressiva da grande cobra, presente para sempre nos peixes, deve ser combatida cotidianamente com cuidadoso cozimento do alimento e cuidados especiais na sua manipulação culinária. A ingestão acidental do sêmen-pitiú pode produzir uma doença consumptiva (whíokali), que cursa com diarréia, 
emagrecimento, palidez e astenia, podendo matar seu portador caso o diagnóstico não seja feito em tempo hábil para instituir o tratamento. Entre as medidas de prevenção da whíokali destaca-se a realização correta do kalidzamai de nascimento e o cozimento prolongado dos peixes com muita pimenta.

Diversos são os meios utilizados pelos Baniwa para classificar os peixes: características morfológicas, preferências de hábitat, hábitos alimentares e reprodutivos. Porém uma das mais importantes formas de classificação está relacionada ao grau de periculosidade desses animais, em especial sua capacidade de gerar doença e morte, que será diretamente proporcional à presença e tamanho de meios de agressão, como dentes e esporões. Reconhece-se que, em maior ou menor intensidade, os peixes partilham com as serpentes a capacidade de morder, eliminar substâncias venenosas, aferroar etc. Tais características demandam a realização de procedimentos que neutralizem esse poder de agressão, tais como kalidzamai realizados no pós-nascimento, na puberdade e na convalescença de doenças graves. O raciocínio de Fausto (2002) permite-nos afirmar que os benzimentos do alimento se propõem a retirar, da presa, sua condição de sujeito; através dessa dessubjetivação, pretendem transformá-la em puro objeto, ou seja, apenas comida, destituída de agência

Essas características das fontes de comida demandam restrição dos alimentos disponibilizados aos doentes e pessoas em situação de liminaridade. Em termos gerais, a sobriedade no comer é importante valor no ethos Baniwa, recomendada tanto aos sãos quanto aos doentes. Porém no caso desses últimos ela assume caráter de imposição, sendo tanto mais restritiva e ampla a dieta quanto mais grave seja a doença e mais semelhante aos grandes predadores seja o peixe. Aos doentes em geral, e em particular aos picados de cobra e envenenados por mánhene, ${ }^{6}$ são interditados os peixes capazes de morder e ferroar, além daqueles cujas características físicas (peixes lisos, viscosos, sem escamas, com peçonha) lembrem as das serpentes. À medida que o quadro se prolongue ou agrave, aumenta a restrição ao consumo de animais de caça e pesca, ${ }^{7}$ particularmente os de grande porte. Interdições similares são feitas aos jovens púberes e aos pais dos recém-natos.

A etiqueta das maneiras à mesa também é parte do conjunto de medidas que visam à redução do perigo alimentar e o reforço aos laços de solidariedade e respeito mútuo. Para o conjunto das fratrias Baniwa, junto às quais coletamos informações, a partilha dos alimentos é um dos comportamentos mais valorizados socialmente. A adequada recepção de visitantes implica oferta de alimentos, cuja qualidade pode variar de acordo com a disponibilidade de comida e a importância atribuída ao visitante. Assim, aos simples transeuntes (ou em época de escassez de alimentos) pode ser oferecido apenas 
um chibé; aos membros de sibs (grupos de consangüíneos que formam uma fratria) e fratrias reconhecidos como importantes na escala social Baniwa, a recepção deve, idealmente, ser acompanhada de uma refeição de peixe ou carne de caça.

Nas áreas dominadas pelas fratrias Walipere e Dzawenai, sobretudo entre os evangélicos, as regras que envolvem a obrigação de partilhar os alimentos, evitar os abusos gastronômicos e valorizar a comensalidade são severas; particularmente porque à partilha do alimento é atribuído o poder de 'agradar' e 'amansar' os estranhos. Ela não somente é um ato de reafirmação de laços de compromisso e solidariedade, mas também uma efetiva demonstração de confiança entre os comensais. É uma negação da possibilidade de envenenamento (mánhene), que para os Baniwa representa uma das principais formas de agressão e morte na convivência social. Partilhar alimento é reafirmar o compromisso com atitudes adequadas a um ser humano, afastar comportamentos canibalescos e anti-sociais, tidos como característicos da alteridade agressiva. Trata-se enfim, de uma ativa política de redução das diferenças.

Aqueles que recusam a comida ofertada ou mostram-se avarentos na partilha dos alimentos são vistos com reserva pelos demais e tendem a ser enquadrados como desviantes. Podem se tornar suspeitos de serem 'donos de veneno' (mánhene iminali) e ser considerados culpados em casos de mortes atribuídas a feitiço, o que não costuma ser explicitado em público, mas sim imputado através das fofocas de aldeia. Em suma, a recusa à comensalidade é um ato anti-social por excelência, um comportamento perigoso, capaz de provocar rupturas no tecido social.

Um dos espaços públicos mais importantes em uma aldeia Baniwa é o 'salão comunitário' (makadapana), onde diariamente reúnem-se os membros das diversas famílias para as refeições coletivas. Ali também se delibera sobre trabalhos conjuntos a serem realizados, atualizam-se os mexericos sobre as pessoas e eventos e exercita-se o poder político. A partilha da comida é o eixo que articula o mosaico de eventos ali transcorridos. Em geral, cada família deve levar parte dos alimentos disponíveis em casa para a refeição coletiva. Pela manhã, logo cedo, toca o sino que chama para a primeira ida ao salão. Na seqüência inicia-se a procissão de mulheres, algumas vezes auxiliadas pelos homens da família quando trazem panelas demasiado pesadas, carregando a contribuição de sua família para a refeição comunitária. Nos dias comuns os recipientes com alimentos são alinhados em uma grande mesa central, e os presentes sentam-se em bancos, que podem estar enfileirados nos dois lados do salão ou, nas aldeias menores, distribuídos ao longo das paredes do prédio. Sentados (homens de um lado e mulheres do outro), os participantes aguardam que os jovens, escalados para a tarefa pela chefia da aldeia (capitão), sirvam a comida em seus 
pratos. A prática cotidiana aprimora a habilidade dos jovens em dividir milimetricamente os alimentos disponíveis, tentando fazêlos render de modo que todos os presentes possam ter, em suas vasilhas, uma pequena porção de cada alimento disponível. Procedimentos semelhantes ocorrem para as bebidas que acompanham a refeição. A mesma seqüência de eventos costuma se repetir na refeição noturna.

A partilha de comida e bebida é obrigação moral, que reafirma diariamente no salão a generosidade e os bons propósitos dos participantes, afugentando a sombra dos comportamentos anti-sociais, particularmente o uso do mánhene, cujo principal veículo de disseminação é a comida.

Em termos objetivos ninguém é realmente obrigado a freqüentar o salão ou a levar sua contribuição em comida, mas fazê-lo com prodigalidade gera muito prestígio. A recusa em participar coloca o transgressor na posição de inimigo, tornando-o alvo de censuras veladas, o que resulta em tal clima de censura moral que praticamente inviabiliza sua convivência na aldeia. Trata-se de um meio de promover o 'aparentamento' e combater as linhas centrífugas de força geradas nos embates e disputas miúdas do cotidiano, que ameaçam permanentemente a coesão social. É uma estratégia de reforço à 'familiarização' dos presentes e de controle da potencial eclosão de relações predatórias entre os membros do grupo local (Fausto, 2002).

A gula e a avareza foram responsáveis pelo drama de Hiwidamitti, que ao aceitar a comida dos mortos inicia uma trajetória rumo às sociedades não-humanas. Por fim resta-lhe apenas a cabeça, como testemunha de uma condição perdida e da impossibilidade de convivência com sua parentela. Em sua nova vida, Hiwidamitti já não é capaz de comer com o irmão; ele come pelo irmão; torna-se incapaz, de cumprir com as obrigações sociais que caracterizam a pessoa humana. A nova vida torna-o duplamente indesejável: por condenar o consangüíneo à fome permanente, perpetrando um fratricídio lento, e por não dispor de meios para contribuir com a produção de alimentos e de parentes, tornando-se consumidor exclusivo dos esforços de terceiros.

As regras de preparo dos alimentos a serem servidos no salão sofrem influência da origem das mulheres que as preparam. Dadas as regras de casamento vigentes entre os Baniwa, as esposas que vivem nas aldeias são oriundas de fratrias de afins. Assim, a vida das mulheres casadas é um permanente processo de 'familiarização', efetuada pelos consangüíneos do marido. No cenário aldeão encontramos um gradiente que contém, em um extremo, as mulheres mais velhas, que há muitos anos vivem na aldeia do esposo; no outro temos as jovens esposas, que enfrentam a difícil transição entre a vida que levavam em sua aldeia de origem e a nova situação 
de esposa submetida a uma sogra que também é uma estrangeira no lugar. A condição feminina, transitante entre os limites externos e internos das relações frátricas, demanda rigoroso acompanhamento das regras de limpeza corporal das produtoras e do alimento por elas preparado, buscando garantir a neutralização da periculosidade inerente a ambos.

A limpeza dos corpos femininos inclui, como pré-requisitos para o preparo da comida, banhos, uso de resinas cheirosas, minuciosa higiene genital e eliminação dos odores corporais; no período menstrual as mulheres devem, idealmente, abster-se da manipulação de alimentos. Procedimentos similares são adotados para a preparação do peixe, cujas vísceras, secreções e odores devem ser igualmente suprimidos. A poluição corporal da mulher é vista como uma via de expressão dos poderes agressivos dos espíritos-animais, e não apenas a ameaça como a todo o grupo de co-residentes. Diversos tipos de afecções, particularmente os transtornos digestivos, são atribuídos à contaminação da comida pela poluição corporal feminina (Garnelo, 2003).

Entre as formas de preparo e consumo do peixe, a quinhãpira, peixe cozido com muita pimenta verde (attimapa), é considerada a forma mais segura e apetitosa de comida. Comidas frias ou ligeiramente requentadas são rejeitadas; a elas atribuem-se propriedades de adoecer as pessoas e propiciar o contato com mundos habitados por animais e seres invisíveis à vivência ordinária. ${ }^{8}$ Idealmente toda comida deveria ser fervida ou moqueada até o ponto de não se evidenciar qualquer indício de sangue no alimento e eliminar vestígios do alimento cru (Lévi-Strauss, 1968). As transgressões a essas condições ideais ocorrem, sendo até relativamente comuns, porém são atos reconhecidos por todos como inadequados, que devem ser evitados. O aparecimento de sintomas de doença é interpretado como sinal de alerta de que o descuido foi longe demais, e nessas ocasiões costuma-se desencadear uma retomada da disciplina alimentar necessária à preservação ou recuperação da saúde.

Às vítimas de picada de cobra e envenenados com mánhene exigese um rigor total no cumprimento das prescrições dietéticas, por parte não apenas delas mas também de seus consangüíneos mais próximos e do cônjuge. O veneno circulante no sangue dessas pessoas representa séria ameaça de transmutação em animal, razão pela qual sua condição humana e seus laços de parentesco precisam ser reafirmados por meio de disciplinas corporais que realçam a capacidade de controlar os impulsos e pela reafirmação dos vínculos sociais com seus semelhantes humanos. 


\section{Considerações finais}

Os dados aqui analisados reafirmam as características das ontologias ameríndias, em que peixes e outros animais são dotados de intencionalidade e assumem posições de sujeitos imersos em uma rede de relações sociais com os seres humanos, negociando, guerreando e interagindo sexualmente. Os homens pescam e consomem peixes, mas também podem ser caçados, agredidos, adoecidos e devorados pelos animais aquáticos que sustentam a reprodução de seu grupo de parentesco. A subjetividade e capacidade de agência dos peixes, serpentes e outros animais aquáticos são plenamente reconhecidas pelo pensamento Baniwa. As interações apreendidas nas narrativas míticas podem ser observadas também em ações cotidianas de pesca e preparo de alimentos, bem como nos cuidados de proteção à saúde e cura de doenças.

Ainda que a literatura disponível sobre o tema tenha voltado sua atenção para os animais de caça, as formas características de viver dos Baniwa propiciaram a produção de um minucioso conhecimento do hábitat aquático e dos seres que nele vivem. O material analisado demonstrou que a interação dos Baniwa com esses animais segue uma lógica similar àquela (já estudada junto a outros povos indígenas) que orienta as relações com os seres terrestres que povoam o espaço natural ao redor. Igualmente permitiu interconectar a produção desses conhecimentos com as formas ordenamento do sistema de cura e cuidados com a saúde desenvolvido pelos membros do grupo.

Comensalidade e predação são movimentos organizadores de uma rede sociocósmica construída em torno da oposição fundamental entre parentes e não-parentes. Eles viabilizam as medidas necessárias à interligação desses termos, imprescindíveis ao processo de gestão de identidades e alteridades. As práticas alimentares garantem a produção de novos parentes mediante a apropriação, material e simbólica, da potência vital dos não-parentes. Essa dinâmica tanto propicia a produção de conhecimentos sobre ecologia local, as técnicas de punção e os preparos culinários, quanto orienta um conjunto de comportamentos tidos como necessários ao exercício da predação, entendida como um complexo sistema de prestações e contraprestações efetuadas entre inimigos que, idealmente, seriam transformados em comensais, garantindo a preservação do interior da vida social (Fausto, 1999).

O trânsito entre as fronteiras da humanidade e o domínio da alteridade é condição de renovação e enriquecimento da sociedade, mas também é fonte de morte, doença e caos. É uma condição que demanda a instauração de procedimentos que tornem essa movimentação menos arriscada, tal como observamos na análise dos ritos pudali e kalidzamai (Wright, 1993; Hill, 1987). Os meios de renovação da vida 
social, obtidos pela retirada da condição volitivo-cognitiva do 'outro' consumido na forma de comida, podem ser obtidos de forma mais segura através das estratégias há milênios engendradas nessa cultura. Ainda assim, eles demandam contra-partidas de privação e sofrimento dos que predam, restaurando, dentro de certos limites, o equilíbrio cósmico instável e perpe-tuamente ameaçado pela voracidade e outros comportamentos anti-sociais.

\section{NOTAS}

${ }^{1}$ A pesquisa vem sendo desenvolvida com apoio do Conselho Nacional de Desenvolvimento Científico e Tecnológico e Ministério do Meio Ambiente, através do projeto Ambiente, Cidadania e Saúde das Mulheres Indígenas do Alto Rio Negro. As atividades de campo são realizadas em parceria com a Organização Indígena da Bacia do Içana (Oibi), através do projeto Kophe Kooyanali, desenvolvido por aquela entidade.

2 De acordo com Wright (1993), o termo Baniwa não é uma autodesignação, porém ao longo do processo colonizatório ele foi incorporado pelos indígenas e tornou-se signo de auto-referência. O autor informa que o mesmo grupo é denominado de Wakuenai na Venezuela e de Curripaco na Colômbia. No médio Içana, Brasil, onde coletei meus dados de campo, os membros desse grupo não costumam usar, em sua vida cotidiana, nenhum termo genérico para descrever o conjunto de sua população. No coletivo referem a si próprios pelo nome de sua fratria de origem; no contato com outros grupos étnicos rionegrinos ou com não-indígenas, costumam designar-se Baniwa.

3 A região onde a pesquisa foi realizada contém também assentamentos Curripaco, grupo que pratica uma variante dialetal da língua Baniwa e que opera para fins práticos como uma fratria, efetuando até mesmo trocas matrimoniais com seus vizinhos mais próximos Walipere e Hohodene.

4 Em outras versões os encarregados dessa tarefa eram denominados Wakaweni, descritos pelos narradores como 'escravos' de Niãpirikoli.

5 O termo familiarização é usado aqui com o sentido proposto por Fausto (2002): tornar familiar, reduzir a diferença e aproximar do plano da consangüinidade um membro da alteridade.

6 Mánhene é um termo que designa simultaneamente uma doença e seu meio instrumental de causalidade. Caracteriza-se pela introdução de substâncias venenosas no corpo da vítima, por meio de comida ou bebida. É considerada pelos Baniwa como a principal e mais perigosa doença que os acomete. A prática de envenenamento é tida como uma forma de feitiçaria, e o envenenador é considerado como um ser anti-social por excelência (Garnelo, 2003)

7 A análise da relação dos Baniwa com animais terrestres e alados é igualmente importante, mas foge ao escopo deste trabalho, para o qual delimitamos o estudo da interação com os animais aquáticos.

8 Diversos mitos narram viagens de pessoas até as povoações subaquáticas dos peixes, onde estes assumem forma humana e vivem de modo similar ao nosso. Em alguns desses relatos o meio de um ser humano comum transportar-se para lá é a ingestão de comida fria e estragada, que viabiliza a comunicação com mundos aos quais apenas os xamãs podem ter acesso através das viagens propiciadas pelo paricá.

\section{REFERÊNCIAS BIBLIOGRÁFICAS}

Arhem, Kaj 2001

Buchillet, Dominique 1988
La red cósmica de la alimentacion. In: Descola, Philippe; Pálsson, Gisli. Naturaleza y sociedad: perspectivas antropologicas. México: Siglo Veintiuno. p.214-236.

Interpretação de doença e simbolismo ecológico entre os índios Desana. Boletim do Museu Paraense Emilio Goeldi, Belém, Série Antropológica, v.4, n.1, p.27-42. 


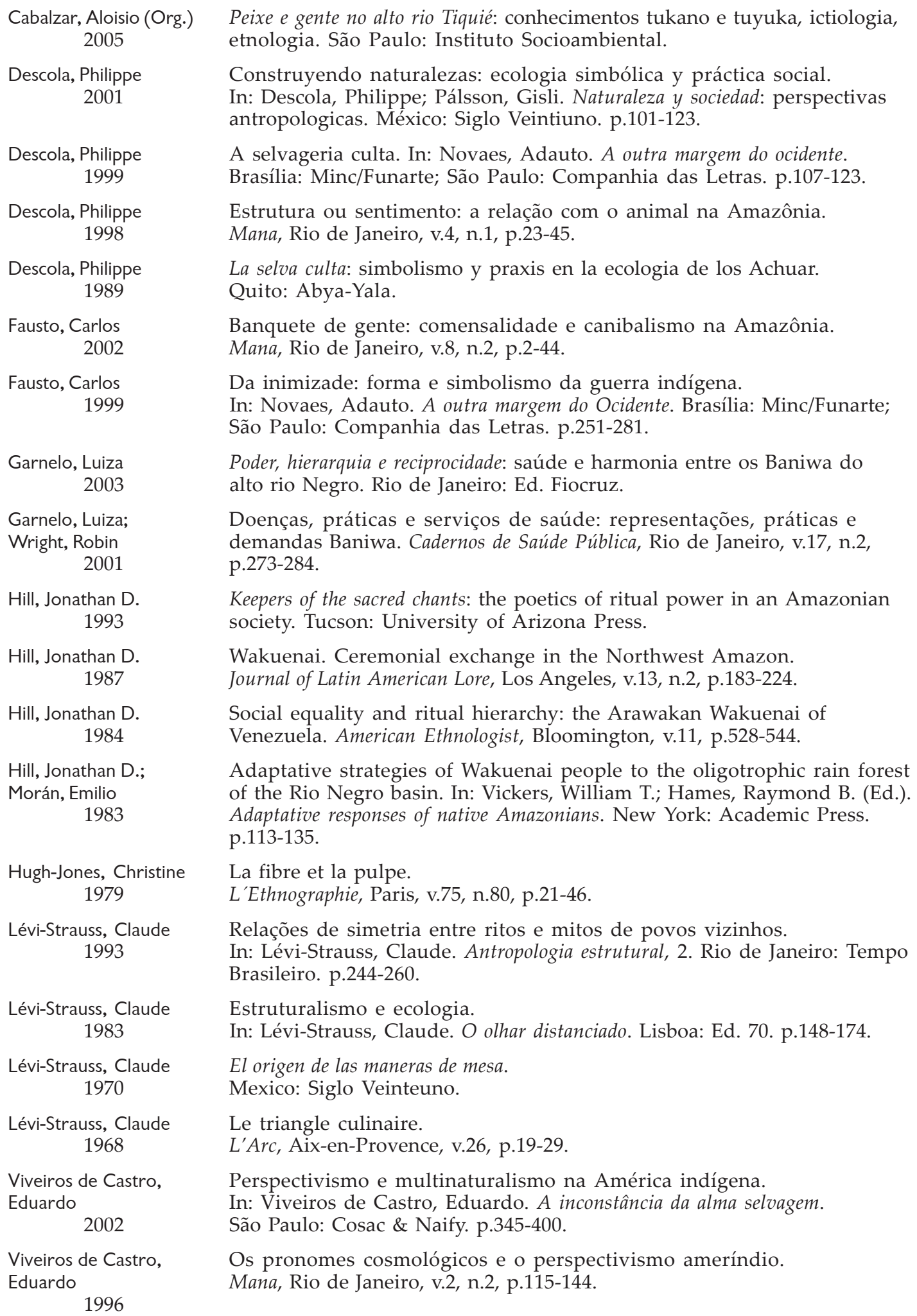


LUIZA GARNELO

Wright, Robin

1998

Wright, Robin

1993-1994

Wright, Robin

1993
Cosmos, self and history in Baniwa religion: for those unborn. Austin: University of Texas Press.

Umawali: Hohodene myths of the anaconda, father of the fish. Bulletin Suisse des Américanistes, Geneva, n.57-58, p.37-48.

Pursuing the spirit: semantic construction in Hohodene Kalidzamai chants for initiation. Amerindia, Paris, v.18, p.1-40.

Recebido para publicação em fevereiro de 2007. 